\title{
Additive effects of glycaemia and dyslipidaemia on risk of cardiovascular diseases in type 2 diabetes: an observational study from the Swedish National Diabetes Register
}

\author{
S. Gudbjörnsdottir • B. Eliasson • K. Eeg-Olofsson • \\ B. Zethelius • J. Cederholm • \\ on behalf of the National Diabetes Register (NDR)
}

Received: 17 February 2011 / Accepted: 16 May 2011 / Published online: 15 June 2011

(C) Springer-Verlag 2011

\begin{abstract}
Aims/hypothesis The study aimed to assess the relative importance of the control of $\mathrm{HbA}_{1 \mathrm{c}}$ and total cholesterol/ HDL-cholesterol ratio (TC/HDL) on risk of cardiovascular disease (CVD).

Methods In 22,135 participants with type 2 diabetes (age 30-75 years, $15 \%$ with previous CVD) followed for 5 years, baseline and annually updated mean $\mathrm{HbA}_{1 \mathrm{c}}$ and TC/HDL were analysed and also categorised in combinations of quartiles. Outcomes were fatal/non-fatal CHD, stroke, CVD and total mortality.

Results In all participants, HRs per 1 SD increase in updated mean $\mathrm{HbA}_{1 \mathrm{c}}$ or $\mathrm{TC} / \mathrm{HDL}$ using Cox regression analysis were $1.13(95 \%$ CI $1.07,1.19)$ and $1.31(1.25$, 1.37) for CHD, $1.15(1.06,1.24)$ and $1.25(1.17,1.34)$ for stroke, $1.13(1.08,1.18)$ and $1.29(1.24,1.34)$ for CVD (all $p<0.001)$, and $1.07(1.02,1-13 ; p=0.01)$ and $1.18(1.12,1.24 ; p<0.001)$ for total mortality, respectively, adjusted for clinical characteristics and traditional risk
\end{abstract}

S. Gudbjörnsdottir · B. Eliasson · K. Eeg-Olofsson

Department of Medicine, Sahlgrenska University Hospital,

Gothenburg University,

Gothenburg, Sweden

B. Zethelius

Department of Public Health and Caring Sciences/Geriatrics,

Uppsala University,

Uppsala, Sweden

J. Cederholm $(\bowtie)$

Department of Public Health and Caring Sciences/Family

Medicine and Clinical Epidemiology, Uppsala University, BMC,

Box 564, SE-751 22 Uppsala, Sweden

e-mail: jan.cederholm@pubcare.uu.se factors. The $p$ value for the interaction between $\mathrm{HbA}_{1 \mathrm{c}}$ and TC/HDL was 0.02 for CHD, 0.6 for stroke and 0.1 for CVD. Adjusted mean 5-year event rates in a Cox model, in combinations of quartiles of updated mean TC/HDL and $\mathrm{HbA}_{1 \mathrm{c}}$ (lowest $<3.1 \mathrm{mmol} / 1$ and $5.0-6.4 \%$ [31$46 \mathrm{mmol} / \mathrm{mol}] ;<3.1 \mathrm{mmol} / 1$ and $\geq 7.8 \%$ [ $\geq 62 \mathrm{mmol} / \mathrm{mol}]$; $\geq 4.6 \mathrm{mmol} / \mathrm{l}$ and $5.0-6.4 \% 31-46 \mathrm{mmol} / \mathrm{mol}$; and highest $\geq 4.6 \mathrm{mmol} / \mathrm{l}$ and $\geq 7.8 \%$ [ $\geq 62 \mathrm{mmol} / \mathrm{mol}]$ ), were $4.8 \%$, $7.0 \%, 9.1 \%$ and $14.5 \%$ for CHD, and $7.1 \%, 9.9 \%, 12.8 \%$ and $19.4 \%$ for CVD, respectively. Adjusted HRs for highest vs lowest combinations were $2.24(1.58-3.18)$ for CHD and $2.43(1.79-3.29)$ for CVD $(p<0.001)$.

Conclusions/interpretation Hyperglycaemia and hyperlipidaemia were less than additive for CHD and additive for other endpoints, with the lowest risk at lowest combination levels and a considerable increase in absolute risk at high combination levels.

Keywords Cardiovascular disease - Diabetes mellitus . Dyslipidaemia $\cdot$ Hyperlipidaemia $\cdot \mathrm{HbA}_{1 \mathrm{c}}$

\begin{tabular}{|c|c|}
\hline \multicolumn{2}{|c|}{ Abbreviations } \\
\hline ACCORD & $\begin{array}{l}\text { Action to Control Cardiovascular Risk in } \\
\text { Diabetes }\end{array}$ \\
\hline ADVANCE & Action in Diabetes and Vascular Disease \\
\hline CVD & Cardiovascular disease \\
\hline ICD & International Classification of Diseases \\
\hline IFCC & International Federation of Clinical Chemistry \\
\hline MI & Myocardial infarction \\
\hline NDR & Swedish National Diabetes Register \\
\hline TC & Total cholesterol \\
\hline UKPDS & UK Prospective Diabetes Study \\
\hline VADT & Veterans Affairs Diabetes Trial \\
\hline
\end{tabular}




\section{Introduction}

Dyslipidaemia is one of the major risk factors for CHD, as has been demonstrated in individuals with type 2 diabetes in large studies such as the UK Prospective Diabetes Study (UKPDS) [1, 2]. Total and LDL-cholesterol have been consistently associated with CHD risk in multiple clinical investigations [1]. The total cholesterol/HDL-cholesterol ratio (TC/HDL) is nowadays commonly used as the preferred risk factor among various lipid measures for analysing the association with cardiovascular disease (CVD) [3], as was also used in the UKPDS regarding the association with both CHD [4, 5] and stroke [6] in individuals with type 2 diabetes.

$\mathrm{HbA}_{1 \mathrm{c}}$ is a well-established risk factor for microvascular diabetic complications [7,8] and also for CVD in type 1 diabetes $[9,10]$. Previous epidemiological studies have shown a positive association between $\mathrm{HbA}_{1 \mathrm{c}}$ and risk of CVD in type 2 diabetes [8,11-13], although some large randomised clinical trials have not been able to show that intensive hypoglycaemic treatment is beneficial with regard to CVD risk [14-16]. However, the long-term follow-up of the UKPDS found, after 10 years, significant risk reductions of $15 \%$ for myocardial infarction (MI) and 13\% for total mortality with intensive glucose therapy compared with conventional therapy during the initial 10 years [17]. A recent observational Swedish National Diabetes Register (NDR) study also found significant risk reductions of $20 \%$ for CHD and $16 \%$ for CVD when comparing individuals with type 2 diabetes with a baseline mean $\mathrm{HbA}_{1 \mathrm{c}}$ of $6.5 \%$ $(48 \mathrm{mmol} / \mathrm{mol})$ vs a mean of $7.5 \%(59 \mathrm{mmol} / \mathrm{mol})$ when followed for 6 years. In addition, the study demonstrated no increased risks of CHD, CVD or total mortality at low $\mathrm{HbA}_{1 \mathrm{c}}$ levels in all participants, as well as in subgroups with a longer duration of diabetes or a history of CVD [18].

The STENO-2 multiple risk factor intervention trial in type 2 diabetes has shown increased benefit by targeting several risk factors simultaneously [19]. However, it remains uncertain whether combined treatment of dyslipidaemia, for example as manifested by TC/HDL, and glycaemia can be performed simultaneously to obtain maximum benefit with regard to the risks of CHD and CVD.

Against this background, we assessed the relative importance of $\mathrm{TC} / \mathrm{HDL}$ and $\mathrm{HbA}_{1 \mathrm{c}}$ as risk factors for fatal/non-fatal CHD, stroke and CVD in an observational study of individuals with type 2 diabetes from a national diabetes register. As macrovascular complications represent a major cause of mortality in type 2 diabetes, with $\mathrm{MI}$ and stroke accounting for about $80 \%$ of all deaths [20], we also assessed the combined effect of control of TC/HDL and $\mathrm{HbA}_{1 \mathrm{c}}$ on risks of fatal CVD and total mortality in a sample in which $15 \%$ of participants had a history of CVD.

\section{Methods}

The Swedish NDR The NDR was initiated in 1996 as a tool for local quality assurance and feedback in diabetes care. Annual reporting to the NDR is carried out by trained physicians and nurses via the Internet or via clinical records databases, with information collected during patient visits to hospital outpatient clinics and primary healthcare centres nationwide. All participants included agreed by informed consent to register before inclusion. The Regional Ethics Review Board at the University of Gothenburg approved this study. Several reports concerning trends in risk factor control and risk prediction in the NDR have previously been published [21-25].

Participants This study consisted of 22,135 female and male participants with type 2 diabetes registered on the NDR who had data available for all analysed variables, with baseline visits in 2002-2003 and follow-up until December 2007. About $20 \%$ of participants registered on the NDR were excluded because of missing data. The inclusion criteria were age range $30-75$ years, $\mathrm{HbA}_{1 \mathrm{c}} \geq 5 \%$ ( $\geq 31 \mathrm{mmol} / \mathrm{mol}$ ), BMI $\geq 18 \mathrm{~kg} / \mathrm{m}^{2}$ and plasma creatinine $<150 \mu \mathrm{mol} / \mathrm{l}$. A history of CVD was present in $15 \%$, a history of heart failure in $4 \%$ and atrial fibrillation in 3\% of participants.

The definition of type 2 diabetes was treatment with diet only, treatment with oral hypoglycaemic agents only, or age of onset of diabetes $\geq 40$ years and treatment with insulin alone or combined with oral agents. Only $0.4 \%$ of participants had an age of onset $<30$ years, and $2 \%$ had an age of onset $<40$ years.

Examinations at baseline Clinical characteristics at baseline in 2002-2003 were age, duration of diabetes, sex, $\mathrm{HbA}_{1 \mathrm{c}}$ value, total cholesterol, HDL-cholesterol, TC/HDL, LDL-cholesterol, triacylglycerol, weight, height, smoking status, systolic blood pressure, cumulative microalbuminuria, plasma creatinine, type of hypoglycaemic treatment, and use of antihypertensive drugs and lipid-lowering drugs. BMI $\left(\mathrm{kg} / \mathrm{m}^{2}\right)$ was calculated as weight $/$ height $^{2}$. A smoker was defined as a participant who smoked one or more cigarettes per day, who smoked tobacco using a pipe, or who had stopped smoking within the previous 3 months. The Swedish standard for blood pressure recording, used in the NDR, is the mean value $(\mathrm{mmHg})$ of two supine readings (Korotkoff $\mathrm{I}-\mathrm{V}$ ) with a cuff of appropriate size, after at least 5 min of rest.

Laboratory analyses of $\mathrm{HbA}_{1 \mathrm{c}}$ and blood lipids were carried out at local laboratories, and $\mathrm{HbA}_{1 \mathrm{c}}$ analyses were quality-assured nationwide by regular calibration with the HPLC Mono S method (Amersham Biosciences, Stockholm, Sweden). In this study, all $\mathrm{HbA}_{1 \mathrm{c}}$ values (Mono $\mathrm{S} \%$ ) were 
converted to the DCCT values (\%) using the formula: $\mathrm{HbA}_{1 \mathrm{c}}(\mathrm{DCCT})=0.923 \times \mathrm{HbA}_{1 \mathrm{c}}($ Mono $\mathrm{S})+1.345 ; R^{2}=0.998$ [26], and also expressed as $\mathrm{HbA}_{1 \mathrm{c}}$ (International Federation of Clinical Chemistry [IFCC]) in millimoles per mole. Microalbuminuria was defined as cumulative (micro- or macroalbuminuria), based on a urinary albumin excretion $>20 \mu \mathrm{g} / \mathrm{min}$ in two out of three consecutive tests.

$\mathrm{HbA}_{1 \mathrm{c}}$ and TC/HDL were measured both at baseline and over time as an updated mean of annual measurements, calculated for each individual from baseline to each year of follow-up, with the last observation carried forward for missing data. In case of an event during follow-up, the period for estimating updated mean $\mathrm{HbA}_{1 \mathrm{c}}$ or updated mean TC/HDL was from baseline to the year before this event occurred. Otherwise, this period was from baseline to the censor year.

Follow-up and definition of endpoints All participants were followed from the baseline examination until a first cardiovascular event or death, or otherwise, until the censor date of 31 December 2007. The endpoints used in this study were: non-fatal or fatal CHD, non-fatal or fatal stroke, non-fatal or fatal CVD, fatal CVD and total mortality. Non-fatal CHD was defined as non-fatal MI (ICD-10 code I21; www.who.int/classifications/icd/en/), unstable angina (ICD-10 code I20.0), percutaneous coronary intervention and/or coronary artery bypass grafting. Fatal CHD was defined as ICD-10 codes I20-I25. Stroke was defined as non-fatal or fatal cerebral infarction, intracerebral haemorrhage or unspecified stroke (ICD-10 codes I61, I63, I64 and I67.9). A CVD event was the composite of CHD and/or stroke, whichever came first, and the same definition was used for a history of CVD before baseline.

Atrial fibrillation diagnosed before or at baseline was defined as ICD-10 code I48, and a history of heart failure was defined as ICD-10 code I50, both used as covariates in all regression analyses.

All events were retrieved by data linkage with the Swedish Cause of Death and Hospital Discharge Registers, which is a reliable validated alternative to revised hospital discharge and death certificates $[27,28]$.

Statistical methods Baseline characteristics are presented as means \pm SD or frequencies in Table 1 . Cox regression analysis was used to estimate HRs with $95 \%$ CIs for the outcomes per $1 \mathrm{SD}$ increase in baseline TC/HDL and $\mathrm{HbA}_{1 \mathrm{c}}$, or in updated mean TC/HDL and $\mathrm{HbA}_{1 \mathrm{c}}$ included as strictly time-dependent covariates (Table 2). The proportional hazards assumption was confirmed for all covariates with the Kolmogorov-type supremum test using re-sampling, and with the test of all time-dependent covariates simultaneously introduced. Interactions be-
Table 1 Baseline characteristics in 22,135 female and male participants with type 2 diabetes, aged $30-75$ years

\begin{tabular}{ll}
\hline Variable & All patients \\
\hline Clinical features & \\
Age (years) & $62 \pm 9$ \\
Diabetes duration (years) & $8 \pm 7$ \\
HbA $_{1 c}(\mathrm{DCCT}), \%$ & $7.3 \pm 1.2$ \\
$\mathrm{HbA}_{1 \mathrm{c}}(\mathrm{IFCC}), \mathrm{mmol} / \mathrm{mol}$ & $56 \pm 13$ \\
TC (mmol/l) & $5.06 \pm 1.0$ \\
HDL-cholesterol (mmol/1) & $1.31 \pm 0.4$ \\
Ratio TC/HDL & $4.13 \pm 1.2$ \\
LDL-cholesterol (mmol/l) & $2.98 \pm 0.9$ \\
Triacylglycerol (mmol/1) & $1.69 \pm 0.8$ \\
Systolic blood pressure (mmHg) & $142 \pm 18$ \\
BMI (kg/m ${ }^{2}$ ) & $29.4 \pm 5.1$ \\
Male sex & $13,060(59.0)$ \\
Smoking & $3,766(17.0)$ \\
Albuminuria (urinary albumin $>20 \mu \mathrm{g} / \mathrm{min})$ & $4,628(20.9)$ \\
Atrial fibrillation & $705(3.2)$ \\
History of cardiovascular disease & $3,386(15.3)$ \\
History of congestive heart failure & $919(4.2)$ \\
Treatment & \\
Antihypertensive drugs & $13,617(61.5)$ \\
Lipid-lowering drugs & $9,451(42.7)$ \\
Hypoglycaemic treatment & \\
Diet only & $5,086(23.0)$ \\
Oral agents only & $8,471(38.3)$ \\
Oral agents and insulin & $4,001(18.1)$ \\
Insulin only & $4,577(20.6)$ \\
\hline
\end{tabular}

Data are means $\pm \mathrm{SD}$, or frequencies $n(\%)$

tween baseline TC/HDL and $\mathrm{HbA}_{1 \mathrm{c}}$, and between updated mean TC/HDL and $\mathrm{HbA}_{1 \mathrm{c}}$, were analysed with Wald $\chi^{2}$ values at maximum likelihood estimation, and a nonsignificant interaction was defined as $p>0.05$ (Table 2).

A Cox regression analysis model was also used to estimate 5-year event rates (1-survival rate) for the outcomes, where model output was the adjusted 5-year event rate for each participant, adjusted for covariates as given in Table 2. Stratification was then performed to achieve adjusted mean 5-year event rates for category combinations by lower or higher quartiles of updated mean TC/HDL, and by lower or higher quartiles of updated mean $\mathrm{HbA}_{1 \mathrm{c}}$ (Fig. 1, Table 3). Subgrouping of event rates by sample intervals has also been used in the Framingham studies [29].

All statistical analyses were performed with SAS version 9.1.3 (SAS Institute, Cary, NC, USA). A $p$ value of $<0.05$ using a two-sided test was considered statistically significant. 
Table $2 \mathrm{HRs}$ in 22,135 individuals with type 2 diabetes per $1 \mathrm{SD}$ increase in baseline or updated mean values of TC/HDL or $\mathrm{HbA}_{1 \mathrm{c}}$

\begin{tabular}{|c|c|c|c|c|c|c|c|}
\hline \multirow[t]{2}{*}{ Outcome } & \multirow[t]{2}{*}{ Type of predictor } & \multirow[t]{2}{*}{ Endpoints $(n)$} & \multicolumn{2}{|l|}{$\mathrm{TC} / \mathrm{HDL}$} & \multicolumn{2}{|l|}{$\mathrm{HbA}_{1 \mathrm{c}}$} & \multirow[t]{2}{*}{$p$ for interaction } \\
\hline & & & HR $(95 \%$ CI $)$ & $p$ value & HR $(95 \%$ CI $)$ & $p$ value & \\
\hline \multirow[t]{2}{*}{ Fatal/non-fatal CHD } & Baseline & 1,607 & $1.19(1.13,1.25)$ & $<0.001$ & $1.10(1.04,1.16)$ & $<0.001$ & 0.02 \\
\hline & Updated mean & 1,607 & $1.31(1.25,1.37)$ & $<0.001$ & $1.13(1.07,1.19)$ & $<0.001$ & 0.02 \\
\hline \multirow[t]{2}{*}{ Fatal/non-fatal stroke } & Baseline & 742 & $1.16(1.08,1.25)$ & $<0.001$ & $1.09(1.01,1.18)$ & 0.03 & 0.7 \\
\hline & Updated mean & 742 & $1.25(1.17,1.34)$ & $<0.001$ & $1.15(1.06,1.24)$ & $<0.001$ & 0.6 \\
\hline \multirow[t]{2}{*}{ Fatal/non-fatal CVD } & Baseline & 2,249 & $1.18(1.13,1.23)$ & $<0.001$ & $1.09(1.04,1.14)$ & $<0.001$ & 0.05 \\
\hline & Updated mean & 2,249 & $1.29(1.24,1.34)$ & $<0.001$ & $1.13(1.08,1.18)$ & $<0.001$ & 0.1 \\
\hline \multirow[t]{2}{*}{ Fatal CVD } & Baseline & 693 & $1.16(1.08,1.25)$ & $<0.001$ & $1.15(1.06,1.24)$ & $<0.001$ & 0.8 \\
\hline & Updated mean & 693 & $1.28(1.20,1.38)$ & $<0.001$ & $1.18(1.10,1.28)$ & $<0.001$ & 0.5 \\
\hline \multirow[t]{2}{*}{ Total mortality } & Baseline & 1,667 & $1.05(1.01,1.11)$ & 0.03 & $1.07(1.01,1.12)$ & 0.02 & 0.8 \\
\hline & Updated mean & 1,667 & $1.18(1.12,1.24)$ & $<0.001$ & $1.07(1.02,1.13)$ & 0.01 & 0.09 \\
\hline
\end{tabular}

HRs were adjusted for age, diabetes duration, sex, systolic blood pressure, BMI, smoking, albuminuria $>20 \mu \mathrm{g} /$ min, antihypertensive drugs, lipidlowering drugs, type of hypoglycaemic treatment, atrial fibrillation, history of CVD and history of heart failure

\section{Results}

Baseline characteristics for all 22,135 participants with type 2 diabetes are given in Table 1 . The age range was $30-75$ years, with mean age and duration of diabetes 62 years and 8 years, respectively. A history of CVD was present in $15 \%$, and a history of heart failure in 4\%. Lipid-lowering drugs were given to $43 \%$ of participants. Treatment with oral hypoglycaemic agents only, insulin combined with oral hypoglycaemic agents and insulin only was given to $38 \%, 18 \%$ and $21 \%$ of individuals. The median (25th-75th percentiles) of updated mean TC/HDL was $4.0(3.25-4.89) \mathrm{mmol} / 1$ and of $\mathrm{HbA}_{1 \mathrm{c}}$ was $7.07 \%(6.42-7.90 \%)(54[47-63] \mathrm{mmol} / \mathrm{mol})$.

Events In all participants, 1,607, 742, 2,249 and 1,667 events of fatal/non-fatal CHD, fatal/non-fatal stroke, fatal/non-fatal CVD and total mortality, respectively, occurred, based on 93,254 person-years during a mean 4.8 years of follow-up. In the four combinations of lowest or highest quartiles of updated mean TC/HDL and $\mathrm{HbA}_{1 \mathrm{c}}$ given in Table 3, the corresponding number of person-years of observation was $5,770,5,329,6,223$ and 6,567 , respectively.
Fig. 1 Mean event rates, adjusted as in Table 3, of outcomes in 22,135 individuals with type 2 diabetes. Values are for 16 different combinations of updated mean $\mathrm{HbA}_{1 \mathrm{c}}(\mathrm{mmol} / \mathrm{l})$ and updated mean ratio of TC/HDL. a Fatal/non-fatal CHD, (b) fatal/ non-fatal stroke, (c) fatal/nonfatal cardiovascular disease and (d) total mortality. All trends of mean event rates by increasing $\mathrm{HbA}_{1 \mathrm{c}}$ per quartile of $\mathrm{TC} / \mathrm{HDL}$, and by increasing TC/HDL per quartiles of $\mathrm{HbA}_{1 \mathrm{c}}$ were significant $(p<0.001)$. HDL-C, HDLcholesterol. To convert values for $\mathrm{HbA}_{1 \mathrm{c}}$ in per cent to millimoles per litre, subtract 2.15 and multiply by 10.929 a

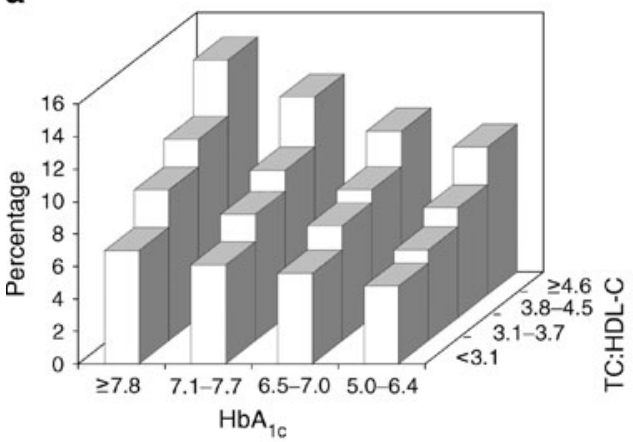

C

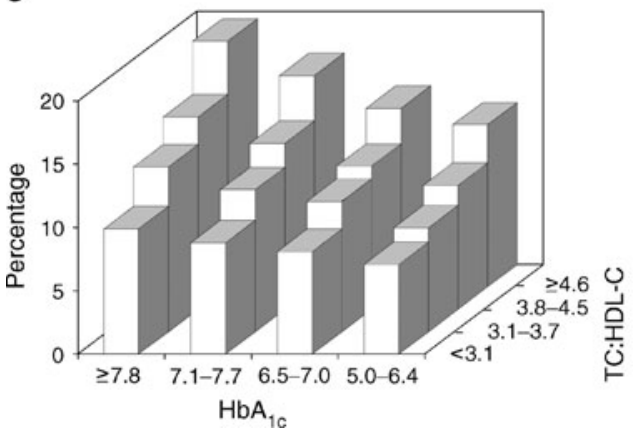

b

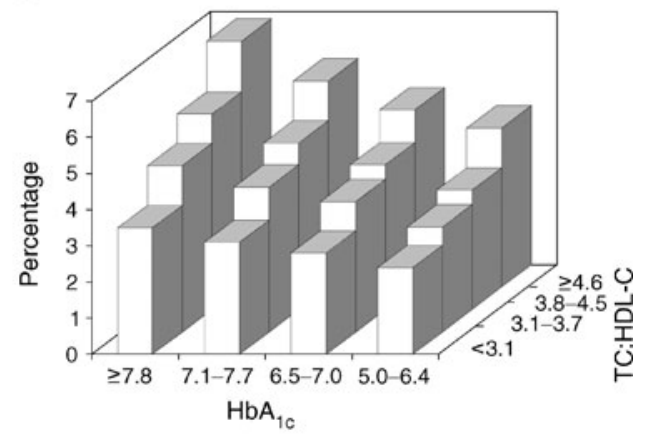

d

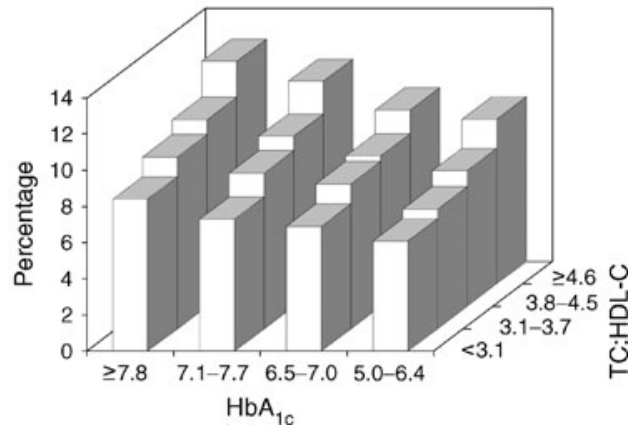


Table 3 Mean event rates for the four lowest or highest combinations of quartiles of updated mean TC/HDL and quartiles of updated mean $\mathrm{HbA}_{1 \mathrm{c}}$

\begin{tabular}{|c|c|c|c|c|c|c|}
\hline \multirow[t]{3}{*}{ Variable } & \multicolumn{4}{|c|}{ Updated mean TC/HDL } & \multirow{2}{*}{\multicolumn{2}{|c|}{$\begin{array}{l}\text { Highest/lowest category } \\
\text { combination }\end{array}$}} \\
\hline & \multicolumn{2}{|l|}{$<3.1 \mathrm{mmol} / 1$} & \multicolumn{2}{|l|}{$\geq 4.6 \mathrm{mmol} / 1$} & & \\
\hline & $\begin{array}{l}\mathrm{HbA}_{1 \mathrm{c}} 5.0-6.4 \% \\
(31-46 \mathrm{mmol} / \mathrm{mol})\end{array}$ & $\begin{array}{l}\mathrm{HbA}_{1 \mathrm{c}} \geq 7.8 \% \\
(\geq 62 \mathrm{mmol} / \mathrm{mol})\end{array}$ & $\begin{array}{l}\mathrm{HbA}_{1 \mathrm{c}} 5.0-6.4 \% \\
(31-46 \mathrm{mmol} / \mathrm{mol})\end{array}$ & $\begin{array}{l}\mathrm{HbA}_{1 \mathrm{c}} \geq 7.8 \% \\
(\geq 62 \mathrm{mmol} / \mathrm{mol})\end{array}$ & HR $(95 \% \mathrm{CI})$ & $p$ value \\
\hline $\mathrm{HbA}_{1 \mathrm{c}}(\mathrm{DCCT})($ mean $\pm \mathrm{SD}), \%$ & $6.1 \pm 0.3$ & $8.6 \pm 0.7$ & $6.1 \pm 0.3$ & $8.8 \pm 0.9$ & & \\
\hline $\mathrm{HbA}_{1 \mathrm{c}}(\mathrm{IFCC})(\mathrm{mean} \pm \mathrm{SD}), \mathrm{mmol} / \mathrm{mol}$ & $43 \pm 4$ & $70 \pm 7$ & $43 \pm 3$ & $72 \pm 10$ & & \\
\hline $\mathrm{TC} / \mathrm{HDL}(\operatorname{mean} \pm \mathrm{SD})$ & $2.7 \pm 0.3$ & $2.6 \pm 0.4$ & $5.4 \pm 0.8$ & $5.5 \pm 0.8$ & & \\
\hline \multicolumn{7}{|l|}{ Endpoints } \\
\hline \multicolumn{7}{|l|}{ Fatal/non-fatal CHD } \\
\hline Number $(n)$ & 1,418 & 1,405 & 1,221 & 1,626 & & \\
\hline Events $(n)(\%)$ & $57(4.0)$ & $84(6.0)$ & $127(10.4)$ & $191(11.8)$ & & \\
\hline Event rate (mean $\pm \mathrm{SD}), \%$ & $4.8 \pm 3.5$ & $7.0 \pm 5.4$ & $9.1 \pm 7.6$ & $14.5 \pm 10.8$ & $2.24(1.58,3.18)$ & $<0.001$ \\
\hline \multicolumn{7}{|l|}{ Fatal/non-fatal stroke } \\
\hline Number $(n)$ & 1,403 & 1,406 & 1,204 & 1,630 & & \\
\hline Events, $n(\%)$ & $23(1.6)$ & $46(3.3)$ & $43(3.6)$ & $96(5.9)$ & & \\
\hline Event rate (mean $\pm \mathrm{SD}), \%$ & $2.4 \pm 1.9$ & $3.5 \pm 2.9$ & $4.4 \pm 4.5$ & $6.8 \pm 6.1$ & $3.11(1.80,5.37)$ & $<0.001$ \\
\hline \multicolumn{7}{|l|}{ Fatal/non-fatal CVD } \\
\hline Number $(n)$ & 1,411 & 1,380 & 1,219 & 1,611 & & \\
\hline Events, $n(\%)$ & $76(5.4)$ & $124(9.0)$ & $161(13.2)$ & $262(16.3)$ & & \\
\hline Event rate $($ mean $\pm \mathrm{SD}), \%$ & $7.1 \pm 5.0$ & $9.9 \pm 7.2$ & $12.8 \pm 9.8$ & $19.4 \pm 13.1$ & $2.43(1.79,3.29)$ & $<0.001$ \\
\hline \multicolumn{7}{|l|}{ Fatal CVD } \\
\hline Number $(n)$ & 1,411 & 1,407 & 1,208 & 1,624 & & \\
\hline Events, $n(\%)$ & $24(1.7)$ & $44(3.1)$ & $46(3.8)$ & $88(5.4)$ & & \\
\hline Event rate $($ mean $\pm \mathrm{SD}), \%$ & $2.0 \pm 3.1$ & $3.6 \pm 5.4$ & $3.7 \pm 6.5$ & $6.8 \pm 9.6$ & $2.35(1.37,4.06)$ & 0.002 \\
\hline \multicolumn{7}{|l|}{ Total mortality } \\
\hline Number $(n)$ & 1,411 & 1,407 & 1,208 & 1,624 & & \\
\hline Events, $n(\%)$ & $88(6.2)$ & $123(8.7)$ & $126(10.4)$ & $170(10.5)$ & & \\
\hline Event rate $($ mean $\pm \mathrm{SD}), \%$ & $6.1 \pm 5.7$ & $8.4 \pm 7.8$ & $9.1 \pm 9.4$ & $12.3 \pm 11.4$ & $1.54(1.12,2.12)$ & 0.008 \\
\hline
\end{tabular}

Mean event rates and HRs were adjusted for age, duration of diabetes, sex, systolic blood pressure, BMI, smoking, albuminuria $>20 \mu \mathrm{g} / \mathrm{min}$, antihypertensive drugs, lipid-lowering drugs, type of hypoglycaemic treatment, atrial fibrillation, history of CVD and history of heart failure

HRs in all participants Table 2 gives adjusted HRs for the outcomes per $1 \mathrm{SD}$ increase in updated mean TC/HDL or $\mathrm{HbA}_{1 \mathrm{c}}$ in all 22,135 participants. Adjustments were made for age, duration of diabetes, sex, systolic blood pressure, BMI, smoking, albuminuria $>20 \mu \mathrm{g} / \mathrm{min}$, type of hypoglycaemic treatment, antihypertensive drugs, lipidlowering drugs, atrial fibrillation, history of CVD and history of heart failure. HRs were higher with TC/HDL as a predictor than with $\mathrm{HbA}_{1 \mathrm{c}}$ as a predictor, and were also higher with updated mean values of the two predictors than with baseline values.

HRs with updated mean TC/HDL and $\mathrm{HbA}_{1 \mathrm{c}}$ values were $1.31(1.25-1.37)$ and $1.13(1.07-1.19)$ for fatal/nonfatal CHD; $1.25(1.17-1.34)$ and $1.15(1.06-1.24)$ for fatal/ non-fatal stroke; $1.29(1.24-1.34)$ and $1.13(1.08-1.18)$ for fatal/non-fatal CVD; $1.28(1.20-1.38)$; and 1.18 (1.10-
1.28) for fatal CVD (all $p<0.001)$. HRs for total mortality were $1.18(1.12-1.24 ; p<0.001)$ and $1.07(1.02-1.13 ; p=$ $0.01)$, respectively.

A subgroup analysis in 18,749 participants with no history of CVD showed similar HRs for all endpoints concerning both baseline and updated mean TC/HDL and $\mathrm{HbA}_{1 \mathrm{c}}$ values.

Interaction tests The test for interaction indicated that the effects on both baseline and updated mean TC/HDL and $\mathrm{HbA}_{1 \mathrm{c}}$ were less than additive for fatal/non-fatal CHD (Wald $\chi^{2}=5.7, p=0.02$ ), and additive for other outcomes, with Wald $\chi^{2}$ for the interaction ranging from 0.5 to 2.8 , and $\mathrm{p}$ values ranging from 0.1 to 0.8 for fatal/non-fatal stroke, fatal/non-fatal CVD, fatal CVD and total mortality (see Table 2). 
Mean event rates in category combinations Figure 1 shows 5 -year mean rates of the outcomes, adjusted for covariates as in Table 2 in a Cox model, in 16 category combinations of quartiles of updated mean TC/HDL and quartiles of updated mean $\mathrm{HbA}_{1 \mathrm{c}}$. The number of participants in each of the 16 category combinations ranged from 1,219 to 1,611 , with a mean number of 1,383 participants. The quartiles of updated mean TC/HDL were $<3.1,3.1-3.7,3.8-4.5$ and $\geq 4.6 \mathrm{mmol} / \mathrm{l}$, and the quartiles of updated mean $\mathrm{HbA}_{1 \mathrm{c}}$ were $5.0-6.4 \% \quad(31-46 \mathrm{mmol} / \mathrm{mol}), 6.5-7.0 \% \quad(47-$ $53 \mathrm{mmol} / \mathrm{mol}$ ), $7.1-7.7 \%$ (54-61 $\mathrm{mmol} / \mathrm{mol})$ and $\geq 7.8 \%$ ( $\geq 62 \mathrm{mmol} / \mathrm{mol}$ ). Gradually increasing mean 5-year rates for all outcomes, CHD, stroke, CVD and total mortality were observed as exposure to $\mathrm{TC} / \mathrm{HDL}$ and $\mathrm{HbA}_{1 \mathrm{c}}$ increased. A somewhat stronger effect of increasing $\mathrm{TC} /$ HDL for each quartile of $\mathrm{HbA}_{1 \mathrm{c}}$ was seen, compared with the effect of increasing $\mathrm{HbA}_{1 \mathrm{c}}$ for each quartile of TC/HDL. There was no sign of increased risk for the outcomes in the lowest combined quartiles of $\mathrm{TC} / \mathrm{HDL}$ and $\mathrm{HbA}_{1 \mathrm{c}}$, concerning CHD, stroke, CVD as well as total mortality.

Table 3 gives events and mean 5-year event rates of the outcomes for four category combinations of the lowest and the highest quartiles of updated mean $\mathrm{TC} /$ $\mathrm{HDL}$ and $\mathrm{HbA}_{1 \mathrm{c}}$. Mean TC/HDL and $\mathrm{HbA}_{1 \mathrm{c}}$ were $2.7 \mathrm{mmol} / 1$ and $6.1 \%(43 \mathrm{mmol} / \mathrm{mol})$ in category combination $1,2.6 \mathrm{mmol} / 1$ and $8.6 \%(70 \mathrm{mmol} / \mathrm{mol})$ in category combination $2,5.4 \mathrm{mmol} / 1$ and $6.1 \%$ (43 $\mathrm{mmol} / \mathrm{mol})$ in category combination 3 and $5.5 \mathrm{mmol} / \mathrm{l}$ and $8.8 \%$ (72 $\mathrm{mmol} / \mathrm{mol})$ in category combination 4 .

Across these four category combinations of updated mean TC/HDL and $\mathrm{HbA}_{1 \mathrm{c}}$, mean 5-year event rates increased from $4.8 \%, 7.0 \%$ and $9.1 \%$ to $14.5 \%$ for fatal/ non-fatal CHD; from $2.4 \%, 3.5 \%$ and $4.4 \%$ to $6.8 \%$ for fatal/non-fatal stroke; from $7.1 \%, 9.9 \%$ and $12.8 \%$ to $19.4 \%$ for fatal/non-fatal CVD; from $2.0 \%, 3.6 \%$ and $3.7 \%$ to $6.8 \%$ for fatal CVD; and from $6.1 \%, 8.4 \%$ and $9.1 \%$ to $12.3 \%$ for total mortality, respectively.

The adjusted HR with the highest-category combination of updated mean TC/HDL and $\mathrm{HbA}_{1 \mathrm{c}}$, compared with the lowest, was 2.24 (1.58-3.18) for fatal/non-fatal CHD, 3.11 (1.80-5.37) for fatal/non-fatal stroke, 2.43 (1.79-3.29) for fatal/non-fatal CVD (all $p<0.001), 2.35$ (1.37-4.06) for fatal CVD $(p=0.002)$ and $1.54(1.12-2.12)$ for total mortality $(p=0.008)$.

\section{Discussion}

This observational study of 22,135 individuals with type 2 diabetes followed for 5 years found that the effect of increasing updated mean TC/HDL on the risk of fatal/nonfatal CHD, stroke and CVD was higher than the effect of increasing updated mean $\mathrm{HbA}_{1 \mathrm{c}}$, although the risk increases caused by both risk factors were strongly significant when adjusted for clinical characteristics, drug treatments and other traditional risk factors. The risk increase for fatal/nonfatal CHD was $31 \%$ per 1 SD increase of TC/HDL and $13 \%$ per $1 \mathrm{SD}$ increase of $\mathrm{HbA}_{1 \mathrm{c}}$, with values of $25 \%$ and $15 \%$ for fatal/non-fatal stroke, and $29 \%$ and $13 \%$ for fatal/ non-fatal CVD, respectively (Table 2).

The findings here of higher risk increases for fatal/nonfatal CHD with TC/HDL than with $\mathrm{HbA}_{1 \mathrm{c}}$ seem to be in accordance with findings from the UKPDS 23 and UKPDS 56 studies concerning individuals with newly developed type 2 diabetes. Cox regression analysis in the UKPDS 23 trial [2] analysing the risk of fatal/non-fatal MI, and using LDL-cholesterol and HDL-cholesterol instead of the TC/ HDL ratio, disclosed that these two lipid measures were entered before $\mathrm{HbA}_{1 \mathrm{c}}$ at stepwise regression. The HRs for the highest third, compared with the lowest third, were higher with LDL-cholesterol, at $2.11 \quad(p<0.001)$, and decreased HDL-cholesterol, at $1.75(p=0.009)$, than with $\mathrm{HbA}_{1 \mathrm{c}}$, which gave a value of $1.71(p=0.01)$. UKPDS 56 [4], analysing the risk of fatal/non-fatal MI, found a higher estimate for a 1-unit increase in logarithmically transformed TC/HDL than for a $1 \%$-unit increase in $\mathrm{HbA}_{1 \mathrm{c}}$. Surprisingly, in the UKPDS 60 study [6], analysing the risk of fatal/ non-fatal stroke using Cox regression analysis in individuals with newly developed type 2 diabetes, $\mathrm{HbA}_{1 \mathrm{c}}$ was not found to be a significant risk factor, whereas TC/HDL was a strong risk factor $(p=0.009)$. However, UKPDS 35 [8] found a $13 \%$ risk increase for stroke per $1 \%$-unit increase in $\mathrm{HbA}_{1 \mathrm{c}}(p=0.03)$. Other studies have also found elevated TC and decreased HDL-cholesterol as risk factors for stroke in individuals with type 2 diabetes [30], and elevated TC/ HDL as a risk factor for stroke in the general population $[31,32]$.

With each distribution of updated mean TC/HDL or updated mean $\mathrm{HbA}_{1 \mathrm{c}}$ divided into quartiles, it was also demonstrated in the current study that combinations of quartiles increased the prediction of risk of CHD, stroke, CVD and total mortality over the use of any single quartile of $\mathrm{TC} / \mathrm{HDL}$ or $\mathrm{HbA}_{1 \mathrm{c}}$. Participants with higher levels of both $\mathrm{TC} / \mathrm{HDL}$ and $\mathrm{HbA}_{1 \mathrm{c}}$ were at greater risk than those with an increase in just one of these risk factors, and at much greater risk than those who had neither of the factors raised (Fig. 1). For example, those with a combination of the highest quartiles of $\mathrm{TC} / \mathrm{HDL}$ and $\mathrm{HbA}_{1 \mathrm{c}}$, compared with those with a combination of the lowest quartiles of TC/HDL and $\mathrm{HbA}_{1 \mathrm{c}}$, had a 2.2-fold increased risk of CHD, a 3.1-fold increased risk of stroke, and a 2.4-fold increased risk of CVD (Table 3).

Figure 1 also shows that there was no increased risk of CHD, stroke, CVD and total mortality with low levels of $\mathrm{TC} / \mathrm{HDL}$ or $\mathrm{HbA}_{1 \mathrm{c}}$. The combination of the lowest quartiles had a TC/HDL value $<3.1$, with a mean of 2.7 , and a $\mathrm{HbA}_{1 \mathrm{c}}$ 
range of $5.0-6.4 \%(31-46 \mathrm{mmol} / \mathrm{mol})$, with a mean of $6.1 \%$ (43 $\mathrm{mmol} / \mathrm{mol}$ ). This category combination also demonstrated the lowest mean 5-year rate for all outcomes.

Furthermore, Fig. 1 demonstrates that the relative increase in mean CVD rate from $\mathrm{HbA}_{1 \mathrm{c}}$ quartiles 1 to 4 was $39 \%$ within TC/HDL quartile 1 , while higher within TC/HDL quartile 4 , it was $51 \%$. Correspondingly, the relative increase from TC/HDL quartiles 1 to 4 was $81 \%$ within $\mathrm{HbA}_{1 \mathrm{c}}$ quartile 1, whereas higher within $\mathrm{HbA}_{1 \mathrm{c}}$ quartile 4 , it was $99 \%$.

Even if $\mathrm{HbA}_{1 \mathrm{c}}$ is a weaker predictor than lipids, as underlined in a recent review [33] and currently under debate [34-36], $\mathrm{HbA}_{1 \mathrm{c}}$ has an obviously strong effect on outcomes risk, even more so with increasing lipid levels. The absolute risk should be emphasised [33, 36]. The absolute increase in CVD risk in the current study was 5\% with $\mathrm{HbA}_{1 \mathrm{c}}$ quartile 4 compared with $\mathrm{HbA}_{1 \mathrm{c}}$ quartile 1 in participants within TC/HDL quartiles 2 or 3 when followed for 5 years, and the corresponding absolute increase in risk was as much as $7 \%$ in participants within TC/HDL quartile 4 (Fig. 1). This was seen here in participants with a mean duration of diabetes of 8 years, as in the Action in Diabetes and Vascular Disease (ADVANCE) [14], Action to Control Cardiovascular Risk in Diabetes (ACCORD) [15] studies and Veterans Affairs Diabetes Trial (VADT) [16].

The effects of TC/HDL and $\mathrm{HbA}_{1 \mathrm{c}}$ on risk of fatal/nonfatal stroke, fatal/non-fatal CVD, fatal CVD and total mortality were found to be additive using Cox regression analysis, with non-significant $p$ values for interaction (Table 2). However, these effects were less than additive for fatal/non-fatal CHD, with $p=0.02$ for interaction. This may be due to pre-existing cardiac tissue damage, which may to some extent prevent further deterioration when combined with high values of both $\mathrm{TC} / \mathrm{HDL}$ and $\mathrm{HbA}_{1 \mathrm{c}}$.

This observational study allowed for an analysis of participants during daily treatment at hospital and primary care clinics nationwide during recent years, with no exclusion criteria regarding risk factors, thus representing what actually took place in routine clinical practice. A major strength of the study is the large number of participants and person-years involved. Laboratory analyses of $\mathrm{HbA}_{1 \mathrm{c}}$ allowed for calibration to a standard. The capture of data on the outcomes was based on reliable and validated national registers of morbidity and mortality. Unmeasured confounding may exist because of unmeasured covariates. However, substantial adjustments were made for age, sex, duration, drug treatments and several traditional cardiovascular risk factors, including albuminuria, representing microangiopathy, as well as atrial fibrillation, history of CVD and heart failure.

In conclusion, this large observational study of individuals with type 2 diabetes has demonstrated progressive risk increases for CVD and total mortality with increased levels of $\mathrm{TC} / \mathrm{HDL}$ and $\mathrm{HbA}_{1 \mathrm{c}}$, and with the lowest risk in the group with the lowest level of both variables. Less than additive effects of the combination of $\mathrm{HbA}_{1 \mathrm{c}}$ and TC/HDL levels were found for $\mathrm{CHD}$, and additive effects for other endpoints. In accordance with the STENO-2 multiple risk factor intervention trial [19], our findings indicate that optimal treatment of both $\mathrm{HbA}_{1 \mathrm{c}}$ and TC/HDL is important in order to reduce the risks of CVD and mortality in type 2 diabetes.

Acknowledgements We thank all regional NDR coordinators, contributing nurses, physicians and participants. The patient organisation Swedish Diabetes Association, and the Swedish Society of Diabetology, supports the NDR. The Swedish Association of Local Authorities and Regions funds the NDR.

S.G. and J.C. designed the study, collected and performed statistical analysis of the data, drafted the article and approved the final version. B.E., K.E.-O. and B.Z. designed and revised the study, and approved the final version.

Duality of interest The authors declare that there is no duality of interest associated with this manuscript.

\section{References}

1. Evaluation, and Treatment of High Blood Cholesterol in Adults (Adult Treatment Panel III) (2001) Executive summary of the third report of the national cholesterol education program (NCEP) expert panel on detection. JAMA 285:2486-2497

2. Turner RC, Millns H, Holman RR, for the United Kingdom Prospective Diabetes Study Group et al (1998) Risk factors for coronary artery disease in noninsulin dependent diabetes mellitus: United Kingdom Prospective Diabetes Study (UKPDS: 23). BMJ 316:823-828

3. D'Agostino R, Vasan RS, Pencina MJ et al (2008) General cardiovascular risk profile for use in primary care. The Framingham Heart Study. Circulation 117:743-753

4. Stevens RJ, Kothari V, Adler AI, Stratton IM, Holman RR, on behalf of the United Kingdom Prospective Diabetes Study (UKPDS) Group (2001) The UKPDS risk engine: a model for the risk of coronary heart disease in type II diabetes (UKPDS 56). Clinical Science 101:671-679

5. Holman RR, Coleman RL, Shine BSF, Stevens RJ (2005) NonHDL cholesterol is less informative than the total-to-HDL cholesterol ratio in predicting cardiovascular risk in type 2 diabetes. Diabetes Care 28:1796-1797

6. Kothari V, Stevens RJ, Holman RR, for the UK Prospective Diabetes Study Group et al (2002) Risk of stroke in type 2 diabetes estimated by the UK Prospective Diabetes Study Risk Engine. UKPDS 60. Stroke 33:1776-1781

7. The Diabetes Control and Complications Trial Research Group (1993) The effect of intensive treatment of diabetes on the development and progression of long-term complications in insulin-dependent diabetes mellitus. N Engl J Med 329:977-986

8. Stratton IM, Adler AI, Neil HA et al (2000) Association of glycaemia with macrovascular and microvascular complications of type 2 diabetes (UKPDS 35): prospective observational study. BMJ 321:405-412

9. Nathan DM, Cleary PA, Backlund JY et al (2005) Intensive diabetes treatment and cardiovascular disease in patients with type 1 diabetes. N Engl J Med 353:2643-2653 
10. Eeg-Olofsson K, Cederholm J, Eliasson B et al (2010) Glycemic control and cardiovascular disease in 7,454 patients with type 1 diabetes. An observational study from the Swedish National Diabetes Register (NDR). Diabetes Care 33:1640-1646

11. Gerstein HC, Pogue J, Mann JF et al (2005) The relationship between dysglycaemia and cardiovascular and renal risk in diabetic and non-diabetic participants in the HOPE Study: a prospective epidemiological analysis. Diabetologia 48:1749-1755

12. Elley CR, Kenealy T, Robinson E, Drury PL (2008) Glycated haemoglobin and cardiovascular outcomes in people with type 2 diabetes: a large prospective cohort study. Diabetes Med 25:12951301

13. Selvin E, Marinopoulos S, Berkenblit G et al (2004) Metaanalysis: glycosylated hemoglobin and cardiovascular disease in diabetes mellitus. Ann Intern Med 141:421-431

14. Patel A, MacMahon S, Chalmers J, the ADVANCE Collaborative Group et al (2008) Intensive blood glucose control and vascular outcomes in patients with type 2 diabetes. N Engl J Med 358:2560-2572

15. Gerstein HC, Miller ME, Byington RP, the Action to Control Cardiovascular Risk in Diabetes Study Group et al (2008) Effects of intensive glucose lowering in type 2 diabetes. N Engl J Med 358:2545-2559

16. Duckworth W, Abraira C, Moritz T et al (2009) Glucose control and vascular complications in veterans with type 2 diabetes. $\mathrm{N}$ Engl J Med 360:129-139

17. Holman RR, Paul SK, Bethel A, Matthews DR, Neil HAW (2008) 10 -year follow-up of intensive glucose control in type 2 diabetes. N Engl J Med 359:1577-1589

18. Eeg-Olofsson K, Cederholm J, Eliasson B et al (2010) New aspects of $\mathrm{HbA} 1 \mathrm{c}$ as a risk factor for cardiovascular diseases in type 2 diabetes: an observational study from the Swedish National Diabetes Register (NDR). J Intern Med 268:471-482

19. Gaede P, Vedel P, Larsen N, Jensen G, Parving H-H, Pedersen O (2003) Multifactorial intervention and cardiovascular disease in patients with type 2 diabetes. N Engl J Med 348:383-393

20. Morrish NJ, Wang SL, Stevens LK et al (2008) Mortality and causes of death in the WHO multinational study of vascular disease in diabetes. Diabetologia 44(Suppl 2):S14-S21

21. Gudbjörnsdottir S, Cederholm J, Nilsson PM, Eliasson B (2003) The National Diabetes Register in Sweden: an implementation of the St. Vincent Declaration for Quality Improvement in Diabetes Care. Diabetes Care 26:1270-1276

22. Eliasson B, Cederholm J, Nilsson P, Gudbjörnsdottir S (2005) The gap between guidelines and reality: type 2 diabetes in a national diabetes register 1996-2003. Diabetes Med 22:1420-1426

23. Cederholm J, Zethelius B, Nilsson PM, Eeg-Olofsson K, Eliasson B, Gudbjörnsdottir S (2009) Effect of tight control of HbA1c and blood pressure on cardiovascular diseases in type 2 diabetes: an observational study from the Swedish National Diabetes Register (NDR). Diabetes Res Clin Pract 86:74-81

24. Nilsson PM, Cederholm J, Gudbjörnsdottir S et al (2009) Smoking as an independent risk factor for myocardial infarction or stroke in type 2 diabetes: a report from the Swedish National Diabetes Register. Eur J Cardiovasc Prev Rehab 16:506-512

25. Eeg-Olofsson K, Cederholm J, Eliasson B et al (2009) Risk of cardiovascular disease and mortality in overweight and obese patients with type 2 diabetes: an observational study in 13,087 patients. Diabetologia 52:65-73

26. Hoelzel W, Weykamp C, Jeppsson JO et al (2004) IFCC reference system for measurement of hemoglobin A1c in human blood and the national standardization schemes in the United States, Japan, and Sweden: a method-comparison study. Clin Chem 50:166-174

27. Merlo J, Lindblad U, Pessah-Rasmussen H et al (2000) Comparison of different procedures to identify probable cases of myocardial infarction and stroke in two Swedish prospective cohort studies using local and national routine registers. Eur J Epidemiol 16:235-243

28. Tunstall-Pedoe H, Kuulasmaa K, Amouyel P, Arveiler D, Rajakangas AM, Pajak A (1994) Myocardial infarction and coronary deaths in the World Health Organization MONICA Project. Registration procedures, event rates, and case-fatality rates in 38 populations from 21 countries in four continents. Circulation 90:583-612

29. Ingelsson E, D'Agostino RB, Vasan RS et al (2007) Clinical utility of different lipid measures for prediction of coronary heart disease in men and women. JAMA 298:776-785

30. Lehto S, Ronnemaa T, Pyörälä K, Laakso M (1996) Predictors of stroke in middle-aged patients with non-insulin-dependent diabetes. Stroke 27:63-68

31. Anderson KM, Odell PM, Wilson PWF, Kannel WB (1990) Cardiovascular disease risk profiles. Am Heart J 121:293-298

32. Wannamethee SG, Shaper AG, Ebrahim S (2000) HDL cholesterol, total cholesterol, and the risk of stroke in middle-aged British men. Stroke 31:1882-1888

33. Yudkin JS, Richter B, Gale EA (2010) Intensified glucose lowering in type 2 diabetes: time for a reappraisal. Diabetologia 53:2079-2085

34. Czupryniak L, Szymańska-Garbacz E, Pawłowski M, SaryuszWolska M, Loba J (2011) Intensified glucose lowering in type 2 diabetes: time for a bolder reappraisal. Diabetologia 54:701-702

35. DeVries JH (2011) Intensified glucose lowering in type 2 diabetes: don't throw the baby out with the bathwater. Diabetologia 54:705706

36. Yudkin JS, Richter B, Gale AM (2011) Intensified glucose lowering in type 2 diabetes. Reply to Czupryniak L, SzymańskaGarbacz E, Pawłowski M et al. [letter], Aizawa T and Funase Y [letter] and DeVries JH [letter]. Diabetologia 54:707-708 